\title{
PENGARUH CORPORATE SOSIAL RESPONSIBILITY TERHADAP KINERJA PERUSAHAAN PADA PERUSAHAAN MANUFAKTUR SYARIAH
}

\author{
Nadya Raina Galuh ${ }^{1}$, Muhamad Umar Mai ${ }^{2}$, Setiawan $^{3 凶}$ \\ 1,2,3 Jurusan Akuntansi, Politeknik Negeri Bandung, Jl. Gegerkalong Hilir, Ds. Ciwaruga, Bandung 40012. \\ $\square_{e-m a i l}$ : setiawan@polban.ac.id
}

\begin{abstract}
The purpose of this study is to investigate how the influence of corporate social responsibility towards the corporate performance in general, and the influence of each subject of the corporate social responsibility. Corporate social responsibility is company's activities in achieving a balance or integrations between the economic, social, and environment development without compromising the expectations of shareholder (obtain profit). In this research corporate performance measured by ROE (return on equity). The samples used in this study are all manufacturing companies enrolled in Indeks Saham Syariah Indonesia listing in 2017 and published the annual report in 2017 by using method of purposive judgement sampling. There are 87 companies that meet the criteria of the study sample. The analysis method used is path analysis. Data collection method used in this research is a method of documentation and literature study method. The results of this study indicate that the disclosure of CSR as in general has a significant effect on the performance of the company with a positive traits. Disclosure of CSR in the economic subject has no significant effect on company performance. Disclosure of CSR in the Environment has a significant effect on the performance of companies with positive traits. Disclosure of CSR in the Social subject has a significant effect on the performance of the company with a positive traits.
\end{abstract}

Keywords: corporate social responsibility, return on equity (ROE), corporate performance, manufacture corporate, Saria Indonesian Stock Exhange.

\begin{abstract}
Abstrak
Tujuan dari penelitian ini adalah untuk mengetahui bagaimana pengaruh corporate social responsibility terhadap kinerja perusahaan secara keseluruhan, maupun pengaruh dari masing-masing bidangnya. Corporate Social Responsibility merupakan aktivitas perusahaan dalam mencapai keseimbangan atau integrasi antara aspek ekonomi, lingkungan, dan sosial tanpa mengesampingkan ekspektasi para pemegang saham (menghasilkan profit). Dalam penelitian ini, kinerja keuangan perusahaan diukur dengan menggunakan ROE (return on equity). Sampel yang digunakan dalam penelitian ini adalah semua perusahaan manufaktur yang terdaftar dalam Indeks Saham Syariah Indonesia pada tahun 2017 dan menerbitkan annual report pada tahun 2017 dengan menggunakan metode purposive judgement sampling. Terdapat 87 perusahaan yang memenuhi kriteria sampel penelitian. Metode analisis yang digunakan pada penelitian ini adalah analisis jalur. Metode pengumpulan data yang digunakan dalam penelitian ini adalah metode dokumentasi dan metode studi pustaka. Hasil penelitian ini menunjukan bahwa pengungkapan CSR secara keseluruhan berpengaruh signifikan terhadap kinerja perusahaan dengan sifat positif. Pengungkapan CSR di bidang Ekonomi tidak berpengaruh signifikan terhadap kinerja perusahaan. Pengungkapan CSR di bidang Lingkungan berpengaruh signifikan terhadap kinerja perusahaan dengan sifat positif. Pengungkapan CSR di bidang Sosial berpengaruh signifikan terhadap kinerja perusahaan dengan sifat positif.
\end{abstract}

Kata kunci: tanggungjawab sosial perusahaan, laba bersih dengan ekuitas pemegang saham, kinerja perusahaan, perusahaan manufaktur, Indeks Saham Syariah Indonesia.

\section{PENDAHULUAN \\ Latar Belakang}

Saat ini perkembangan yang terjadi pada perusahaan-perusahaan manufaktur di Indonesia sangat pesat. Perusahaan manufaktur merupakan sebuah cabang bisnis yang menerapkan peralatan, mesin, dan tenaga kerja, serta sebuah medium proses yang mengubah bahan mentah menjadi barang setengah jadi atau hingga barang siap jual. Pesatnya perkembangan pada perusahaan-perusahaan manufaktur di Indonesia sejalan dengan upaya dari 
pemerintah untuk menjadikan ekonomi Indonesia berfokus pada sektor non migas. Pertumbuhan Sektor manufaktur Indonesia menjadi yang terbaik di Asia Tenggara. Selain membawa banyak dampak positif bagi perusahaan juga membuat adanya kerusakan lingkungan dan juga menimbulkan kesenjangan sosial. Dampak negatif yang timbul ini merupakan pemicu bagi perusahaan-perusahaan manufaktur untuk melakukan pertanggung jawaban atas kegiatan-kegiatan yang dijalankan melalui corporate social responsibility atau CSR.

CSR di indonesia bermula pada akhir tahun 1990. Kondisi penting yang melatar belakangi lahirnya CSR di Indonesia adalah karena gerakan sosial berupa tekanan dari LSM lingkungan, LSM buruh, serta LSM Perempuan. Selain itu juga karena adanya kesadaran untuk menjalankan praktik CSR dari perusahaan. Program CSR sudah mulai bermunculan di Indonesia seiring telah disahkannya Undang-Undang Nomor 40 Tahun 2007 tentang Perseroan Terbatas dan Undang-Undang Nomor 25 Tahun 2007 tentang Penanaman Modal. Kedua undangundang ini mengharuskan perusahaan untuk melaksanakan kegiatan tanggungjawab sosial perusahaan dan juga mewajibkan perusahaan untuk melaporkan kegiatannya. Kewajiban ini membuat perusahaan manufaktur harus melaksanakan kegiatan CSR. Pada sisi lain pelaksanaan CSR merupakan kegiatan yang membutuhkan dana yang besar. Kegiatan ini memiliki potensi mengurangi keuntungan bagi perusahaan. Berkurangnya keuntungan ini sangat mungkin terjadi karena kegiatan CSR membutuhkan dana yang besar.

Seperti yang telah dijelaskan bahwa perusahaan manukaftur merupakan perusahaan yang mengolah bahan mentah menjadi barang setengah jadi ataupun barang jadi, Industri manufaktur bukan hanya memberikan dampak positif tetapi juga memberikan dampak negatif khusunya kepada masyarakat dan lingkungan.

Masyarakat di sekitar perusahaan manufaktur mendapat dampak positif yaitu adanya lapangan pekerjaan, tetapi pada kenyataannya banyak sekali pendatang yang ingin bekerja pada perusahaan manufaktur yang membuat persaingan menjadi sangat ketat dan pada akhirnya lapangan pekerjaan tetap saja sulit untuk didapatkan. Dampak positif yang seharusnya didapatkan oleh masyarakat di sekitar perusahaan manufaktur tidak terlaksana dengan baik. Apabila perusahaan tidak memperhatikan seluruh factor yang mengelilinginya, mulai dari karyawan, konsumen, lingkungan, dan sumber daya alam sebagai satu kesatuan yang saling mendukung suatu sistem, maka tindakan itu akan mengakhiri eksistensi perusahaan itu sendiri, menurut Mahrun dalam Sueb [1], citra dari sebuah perusahaan akan semakin baik di mata masyarakat apabila dapat menunjukkan tanggung jawab dan kepeduliannya terhadap lingkung eksternal.

Dengan dilaksanakannya CSR maka perusahaan dapat meningkatkan kinerjanya karena para investor cenderung menanamkan modal kepada perusahaan yang melakukan kegiatan CSR. Oleh karena itu, perusahaan-perusahaan yang memiliki kepedulian sosial dapat menggunakan informasi tanggung jawab sosial (kegiatan CSR) sebagai salah satu keunggulan kompetitif perusahaan [2]. Kewajiban melaksanakan CSR bagi perusahaan yang telah disahkan melalui undang-undang yang membuat perusahaan wajib melaksakan kegiatan ini yang berarti perusahaan harus mengeluarkan dana atau biaya yang besar untuk memenuhi kewajibannya ini. Namun pada sisi lain kegiatan ini dapat membangun image perusahaan dan menarik investor untuk menanamkan modalnya dan akan kembali menambah keuntungan bagi perusahaan membuat penulis tertarik untuk 
meneliti hubungan yang terjadi di antara CSR terhadap kinerja perusahaan.

\section{Pengembangan Hipotesis}

Konsep tanggung jawab sosial perusahaan (CSR) berkaitan dengan penyeimbangan masalah sosial, lingkungan dan ekonomi dalam operasi perusahaan [3]. Aktivitas CSR yang dilakukan oleh perusahaan akan berdampak terhadap kinerja perusahaan sesuai dengan penelitian Dahlia dan Siregar [4]. Penelitian ini meneliti pengaruh aktivitas CSR terhadap ROE 1 tahun ke depan karena aktivitas CSR berdampak secara tidak langsung terhadap kinerja perusahaan. Hal ini karena diduga aktivitas CSR dapat menjadi elemen yang menguntungkan sebagai strategi perusahaan, memberikan kontribusi kepada manajemen risiko dan memelihara hubungan yang dapat memberikan keuntungan jangka panjang bagi perusahaan sesuai dengan penelitian Heal [5]. Berdasarkan uraian di atas, maka hipotesis yang dapat dirumuskan adalah:

H1: Pengungkapan aktivitas CSR (CSR disclosure) berpengaruh positif terhadap Kinerja Keuangan Perusahaan (ROE).

CSR terbagi kedalam beberapa bidang dalam memudahkan perusahaan untuk menjalankannya. Salah satu bidang yang paling terpengaruh adalah lingkungan, karena lingkungan merupakan salah satu aspek yang berhubungan secara lagsung dengan kegiatan yang dilakukan perusahaan. Kegiatan CSR terhadap lingkungan memberikan keuntungan bagi perusahaan antara lain yaitu sebagai berikut:

(i) Pengembangkan reputasi atau citra perusahaan di mata konsumen dan investor; (ii) Mengeliminasi konflik lingkungan dan sosial disekitar perusahaan; (iii) Meningkatkan kerja sama dengan para pemangku kepentingan; (iv) Membedakan perusahaan dengan pesaingnya.

Selain bidang lingkungan, bidang ekonomi dan sosial juga merupakan bidang yang sangat terpengaruh dan mempengaruhi dalam proses produksi perusahaan. Karena kedua aspek ini tidak dapat lepas dari masyarakat yang berhubungan langsung dengan perusahaan. Masyakat merupakan salah satu stakeholders dengan pengaruh yang paling kuat. Perusahaan biasanya sangat memerhatikan bidang ekonomi dan sosial masyarakat ini, oleh sebab itu dirumuskan hipotesis sebagai berikut:

H2.1: Pengungkapan aktivitas CSR (CSR disclosure) dalam bidang ekonomi berpengaruh positif terhadap Kinerja Keuangan Perusahaan (ROE).

H2.2: Pengungkapan aktivitas CSR (CSR disclosure) dalam bidang lingkungan berpengaruh positif terhadap Kinerja Keuangan Perusahaan (ROE).

\section{H2.3: Pengungkapan aktivitas CSR (CSR disclosure) dalam bidang sosial berpengaruh positif terhadap Kinerja Keuangan Perusahaan (ROE).}

\section{METODE PENELITIAN}

Penelitian ini menggunakan pendekatan analisis data kuantitatif. Data diperoleh dari semua perusahaan manufaktur yang tercatat di Indeks Saham Syariah (ISSI) tahun 2017. Metode pemilihan sampel dalam penelitian ini adalah metode purposive judgement sampling. Kriteria yang digunakan adalah (i) Perusahaan manufaktur yang listing pada tahun 2017 di ISSI; (ii) Menerbitkan annual report pada tahun 2017; serta (iii) Memiliki data yang lengkap terkait dengan variabelvariabel yang diteliti. Sehingga diperoleh 87 perusahaan sebagai sampel.

Metode analisis yang digunakan dalam penelitian ini menggunakan pendekatan Partial Least Square dengan bantuan aplikasi WarpPLS. 
HASIL DAN PEMBAHASAN

\section{Pengembangan Model}

Model teoritis yang telah digambarkan kemudian dibuat menjadi path diagram. Path diagram ini menunjukan hubunganhubungan antar konstruk yang dapat dilihat melalui anak panah. Anak panah yang lurus akan menunjukan hubungan kausal yang langsung antar konstruk. Sedangkan garisgaris lengkung antar konstruk dengan anak panah pada setiap ujungnya menunjukkan korelasi antar konstruk.

Berikut hasil pengujian dari pengembangan model pengaruh langsung antara CSR dan ROE seperti disajikan di bawah ini.

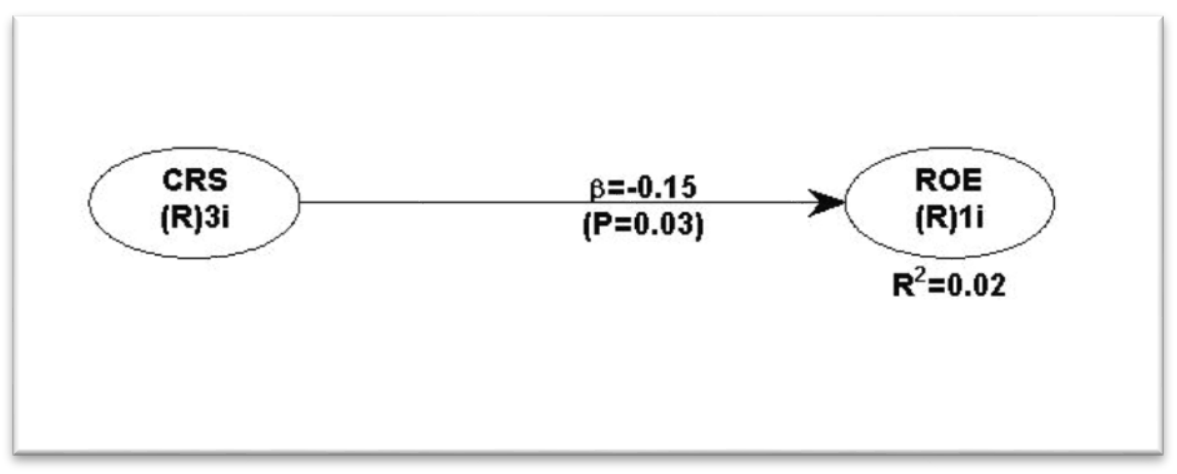

Gambar 1. Pengujian Model Direct Effect

Dari model yang digambarkan dalam diagram jalur diatas diuji pengaruh antara CSR secara keseluruhan terhadap ROE (Kinerja Perusahaan). Terlihat bahwa pengaruh antara CSR (Corporate Social Responsibility) terhadap ROE (Kinerja
Perusahan) signifikan, dengan nilai koefisien jalur sebesar $-0,15$ dengan p-value 0,03. Terdapat pengaruh langsung dari CSR yang secara signifikan mempengaruhi Kinerja Perusahaan.

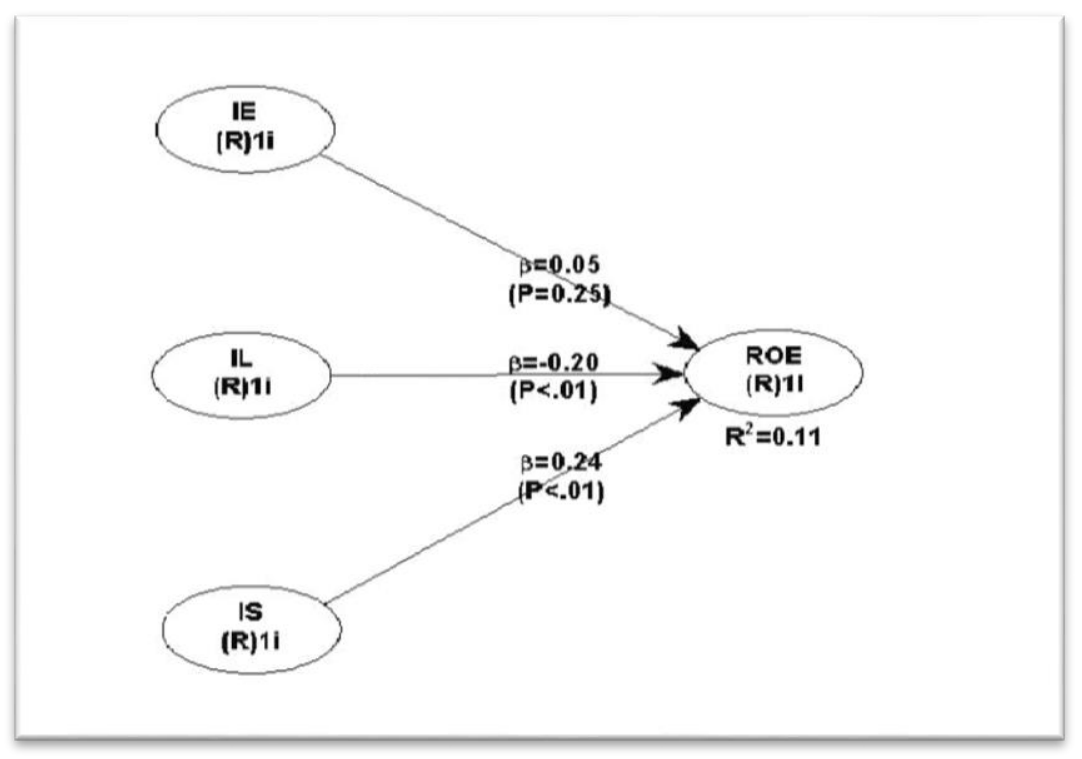

Gambar 2. Pengujian Model Direct Effect

Dalam model yang ditunjukan oleh diagram jalur diatas diuji pengaruh antara IE (CSR dalam bidang Ekonomi), IL (CSR dalam bidang Lingkungan), dan IS (CSR dalam bidang Sosial) secara masing-masing terhadap ROE (Kinerja Perusahaan). Didapatkan hasil sebagai berikut:

1) Pengaruh antara IE (Corporate Social Responsibility dalam bidang Ekonomi) 
terhadap ROE (Kinerja Perusahaan) tidak signifikan, dengan nilai koefisien jalur sebesar 0,05 dan p-value 0,25.

2) Pengaruh antara IL (Corporate Social Responsibility dalam bidang Lingkungan) terhadap ROE (Kinerja Perusahaan) signifikan, dengan nilai koefisien -0,20 dan $p$-value $<0,01$.

3) Pengaruh antara IS (Corporate Social Responsibility dalam bidang Sosial) terhadap ROE (Kinerja Perusahaan) signifikan, dengan nilai koefisien jalur sebesar 0,24 dan $p$-value <0,01.

Dari hasil pengujian yang telah dilakukan ditunjukan adanya pengaruh langsung yang signifikan antara CSR secara keseluruhan terhadap kinerja keuangan (ROE), juga antara CSR bidang Lingkungan dan CSR bidang Sosial secara masing-masing terhadap Kinerja Perusahaan (ROE). Serta tidak terdapat perngaruh langsung yang signifikan antara CSR bidang ekonomi terhadap Kinerja Perusahaan (ROE).

\section{Pengujian Goodness of Fit Model}

Ketepatan fungsi regresi sampel yang diuji dalam menaksir nilai aktual diperiksa atau diuji dengan uji kelayakan yang dikenal sebagai pengujian Goodness of Fit Model. Fit atau tidaknya sebuah model akan dilihat dari hasil nilai Average path coefficient (APC), Average R-squared (ARS), Average adjusted $R$-squared (AARS), Average block VIF (AVIF), Average full collinearity VIF (AFVIF), Tenenhaus GoF (GoF), Sympson's paradox ratio (SPR), $R$-squared contribution ratio (RSCR), Statistical suppression ratio (SSR), dan Nonlinear bivariate causality direction ratio (NLBCDR).

1) Uji Goodness of Fit Model pada model pengujian CSR secara keseluruhan terhadap Kinerja Perusahaan (ROE)

\section{Model fit and quality indices}

Average path coefficient $(\mathrm{APC})=0.148, \mathrm{P}=0.017$

Average $\mathrm{R}$-squared $(\mathrm{ARS})=0.022, \mathrm{P}=0.196$

Average adjusted R-squared (AARS) $=0.011, \mathrm{P}=0.224$

Average block VIF (AVIF) not available

Average full collinearity VIF (AFVIF) $=1.000$, acceptable if $<=5$, ideally $<=3.3$

Tenenhaus $\mathrm{GoF}(\mathrm{GoF})=0.137$, small $>=0.1$, medium $>=0.25$, large $>=0.36$

Sympson's paradox ratio (SPR) $=1.000$, acceptable if $>=0.7$, ideally $=1$

R-squared contribution ratio (RSCR) $=1.000$, acceptable if $>=0.9$, ideally $=1$

Statistical suppression ratio (SSR) $=1.000$, acceptable if $>=0.7$

Nonlinear bivariate causality direction ratio $(\mathrm{NLBCDR})=0.000$, acceptable if $>=0.7$

Gambar 3. Hasil Pengujian Goodness of Fit Model

Dari hasil pengujian diatas menunjukan bahwa nilai APC sebesar 0,148 dan nilai $\mathrm{p}$ value sebesar 0,017; nilai ARS sebesar 0,022 dan nilai $p$-value sebesar 0,196 ; nilai AARS sebesar 0,011 dan nilai $p$-value sebesar 0,224; nilai AVIF yang tidak tersedia; nilai AFVIF sebesar 1,0 yang dapat diterima apabila bernilai $<=5$ dengan nilai ideal sebesar $<=3,3$; nilai GoF sebesar 0,137 yang termasuk ke dalam kriteria small (kecil); nilai SPR sebesar 1,0 yang dapat diterima apabila bernilai $>=0,7$ dengan nilai ideal $=1$; nilai RSCR sebesar 1,0 yang dapat diterima apabila bernilai $>=0,9$ dengan nilai ideal $=1$; nilai SSR sebesar 1,0 yang dapat diterima apabila bernilai $>=0,7$; nilai NLBCDR senilai 0,0 yang dapat diterima apabila bernilai $>=0,7$.

Pada uji kecocokan model terdapat 3 indeks pengujian, yaitu average path coefficient (APC), average $R$-squared (ARS) dan 
Nadya R.G, M. Umar Mai, dan Setiawan, Pengaruh Corporate Social Responsibility...

average varians factor (AVIF) dengan kriteria APC dan ARS diterima dengan syarat $p$-value $<0,05$ dan AVIF $<5$. Sehingga dapat disimpulkan bahwa model fit dan dapat diterima. bidang Lingkungan dan CSR bidang Sosial secara masing-masing terhadap Kinerja Perusahaan (ROE)

2) Uji Goodness of Fit Model pada model pengujian CSR bidang Ekonomi, CSR

Model fit and quality indices

Average path coefficient $(\mathrm{APC})=0.166, \mathrm{P}=0.010$

Average $\mathrm{R}$-squared $(\mathrm{ARS})=0.105, \mathrm{P}=0.048$

Average adjusted $\mathrm{R}$-squared $(\mathrm{AARS})=0.073, \mathrm{P}=0.092$

Average block VIF (AVIF) $=1.014$, acceptable if $<=5$, ideally $<=3.3$

Average full collinearity VIF (AFVIF) $=1.523$, acceptable if $<=5$, ideally $<=3.3$

Tenenhaus $\mathrm{GoF}(\mathrm{GoF})=0.324$, small $>=0.1$, medium $>=0.25$, large $>=0.36$

Sympson's paradox ratio (SPR) $=1.000$, acceptable if $>=0.7$, ideally $=1$

$\mathrm{R}$-squared contribution ratio $(\mathrm{RSCR})=1.000$, acceptable if $>=0.9$, ideally $=1$

Statistical suppression ratio (SSR) $=1.000$, acceptable if $>=0.7$

Nonlinear bivariate causality direction ratio $(\mathrm{NLBCDR})=0.500$, acceptable if $>=0.7$

Gambar 4. Pengujian Goodness of Fit Model

Dari hasil pengujian diatas menunjukan bahwa nilai APC sebesar 0,166 dan nilai pvalue sebesar 0,010; nilai ARS sebesar 0,105 dan nilai $p$-value sebesar 0,048 ; nilai AARS sebesar 0,073 dan nilai p-value sebesar 0,092; nilai AVIF sebesar 1,014 yang dapat diterima apabila bernilai $<=5$ dengan nilai ideal $<=3,3$; nilai $\mathrm{AFVIF}$ sebesar 1,523 yang dapat diterima apabila bernilai $<=5$ dengan nilai ideal sebesar $<=3,3$; nilai GoF sebesar 0,324 yang termasuk ke dalam kriteria medium (sedang); nilai SPR sebesar 1,0 yang dapat diterima apabila bernilai $>=0,7$ dengan nilai ideal $=1$; nilai RSCR sebesar 1,0 yang dapat diterima apabila bernilai $>=0,9$ dengan nilai ideal $=1$; nilai SSR sebesar 1,0 yang dapat diterima apabila bernilai $>=0,7$; nilai NLBCDR senilai 0,5 yang dapat diterima apabila bernilai $>=0,7$.

Pada uji kecocokan model terdapat 3 indeks pengujian, yaitu average path coefficient (APC), average R-squared (ARS) dan average varians factor (AVIF) dengan kriteria APC dan ARS diterima dengan syarat $p$-value $<0,05$ dan AVIF $<5$. Dari data di atas dapat disimpulkan bahwa model fit dan dapat diterima.

\section{Pengujian Hipotesis Hipotesis 1}

Pengaruh antara CSR secara keseluruhan terhadap ROE signifikan, dengan nilai koefisien jalur sebesar $-0,15$ dengan $p$-value 0,03 . Karena p-value $<0,05$ maka $\mathrm{Ha}$ diterima. CSR secara keseluruhan berpengaruh langsung terhadap kinerja perusahaan.

\section{Hipotesis 2.1}

Pengaruh antara CSR bidang Ekonomi secara tersendiri terhadap ROE tidak signifikan, dengan nilai koefisien jalur sebesar 0,05 dan p-value 0,25. Karena pvalue $>0,05$ maka Ho diterima. CSR bidang 
Ekonomi tidak berpengaruh langsung terhadap Kinerja Perusahaan.

\section{Hipotesis 2.2}

Pengaruh antara CSR bidang Lingkungan secara tersendiri terhadap ROE signifikan, dengan nilai koefisien $-0,20$ dan p-value $<0,01$. Karena $p$-value $<0,05$ maka $\mathrm{Ha}$ diterima. CSR bidang Lingkungan berpengaruh langsung terhadap Kinerja Perusahaan.

\section{Hipotesis 2.3}

Pengaruh antara CSR bidang Sosial secara tersendiri terhadap ROE signifikan, dengan nilai koefisien jalur sebesar 0,24 dan $p$-value $<0,01$. Karena p-value <0,05 maka Ha diterima. CSR bidang Sosial berpengaruh langsung terhadap Kinerja Perusahaan.

\section{Pembahasan Hasil Penelitian}

\section{Pengaruh CSR terhadap Kinerja Perusahaan yang diukur menggunakan ROE}

Berdasarkan hasil output warpPLS, hasil penelitian pada persamaan 1 menunjukan bahwa variabel CSR berpengaruh signifikan terhadap Kinerja Perusahaan yang diukur dengan ROE pada perusahaan manufaktur yang terdaftar di ISSI tahun 2017. Hal ini ditunjukan oleh nilai p-valuenya sebesar 0,03 yang memenuhi kriteria signifikansi yaitu sebesar $<0.05$.

Variabel CSR juga memiliki pengaruh positif terhadap variabel Kinerja Perusahaan yang dapat diamati melalui nilai path coeffisien yang bernilai positif senilai 0,15 . Hasil $R^{2}$ dari pengujian ini bernilai 0,02 atau sebesar 2\%. Hasil tersebut menunjukan bahwa CSR hanya mempengaruhi Kinerja Perusahaan yang diukur menggunakan ROE sebesar 2\% sedangkan sisanya yaitu sebesar 98\% dipengaruhi oleh variabel lainnya di luar penelitian ini.

Pengaruh positif yang signifikan pada pengujian hipotesis ini menunjukan bahwa semakin besar pengungkapan yang dilakukan perusahaan atas kegiatan CSRnya maka akan semakin meningkat ROE dari perusahaan tersebut. Walaupun biaya yang dikeluarkan dalam melaksanakan kegiatan CSR besar, namun dampak positif dari baiknya citra perusahaan akan membawa keuntungan yang lebih besar. Semakin luasnya pengungkapan kegiatan CSR akan memberikan sinyal positif kepada pihak-pihak yang berkepentingan terhadap perusahaan maupun para pemegang saham (shareholder).

\section{Pengaruh CSR bidang Ekonomi terhadap Kinerja Perusahaan yang diukur menggunakan ROE}

Berdasarkan hasil output warpPLS, hasil penelitian pada model ini menunjukkan bahwa variabel CSR bidang Ekonomi tidak berpengaruh signifikan terhadap Kinerja Perusahaan yang diukur dengan ROE pada perusahaan manufaktur yang terdaftar di ISSI tahun 2017. Hal ini ditunjukan oleh nilai $p$-value-nya sebesar 0,25 yang tidak memenuhi kriteria signifikansi karena nilainya $>0.05$.

Menurut Chahal dan Sharma [6] aspek ekonomi dari CSR meliputi dampak ekonomi dari kegiatan operasional yang dilakukan oleh perusahaan. Aspek ini sering kali disalah artikan sebagai masalah keuangan perusahaan sehingga aspek ini diasumsikan lebih mudah untuk diimplementasikan daripada dua aspek lainnya, yaitu aspek sosial dan lingkungan menurut Aryawan, Ekawati dan Rahyuda [7].

Penyalahartian ini menyebabkan kegiatan CSR dalam bidang Ekonomi seringkali diabaikan. Atau kalaupun kegiatannya dijalankan namun perusahaan tidak mengungkapkan kegiatan tersebut di dalam laporan CSR-nya melainkan hanya mencantumkannya dalam laporan keuangan. Kesalahan pengungkapan inipun banyak dilakukan perusahaan yang hanya 
Nadya R.G, M. Umar Mai, dan Setiawan, Pengaruh Corporate Social Responsibility...

membuat laporan CSR yang tidak mengandung informasi yang mendetail.

\section{Pengaruh CSR bidang Lingkungan terhadap Kinerja Perusahaan yang diukur menggunakan $\mathrm{ROE}$}

Variabel CSR bidang lingkungan berpengaruh signifikan terhadap Kinerja Perusahaan yang diukur dengan ROE pada perusahaan manufaktur yang terdaftar di ISSI tahun 2017. Hal ini ditunjukan oleh nilai p-valuenya sebesar $<0,01$ yang memenuhi kriteria signifikansi yaitu sebesar $<0.05$. Variabel CSR bidang Lingkungan juga memiliki pengaruh negatif terhadap variabel Kinerja Perusahaan yang dapat diamati melalui nilai path coeffisien yang bernilai negatif senilai $-0,20$.

Negatifnya hasil penelitian CSR bidang lingkungan terhadap kinerja perusahaan ini dapat terjadi karena pengurangan nilai keuntungan akibat penggunaan dana untuk melaksanakan CSR bidang lingkungan. Namun tidak menutup kemungkinan bahwa perusahaan besar yang melaksanakan kegiatan CSR bidang lingkungan sebetulnya mendapatkan keuntungan melalui perbaikan citra yang berdampak pada pendapatan namun dihasilkan hasil negatif karena perhitungan ROE nya yang menunjukan demikian. Karena ROE merupakan perbandingan antara Earning After Tax (EAT) terhadap Equity, maka apabila total ekuitas perusahaan memang besar bisa timbul hasil negatif walaupun EAT yang dimiliki suatu perusahaan sebetulnya meningkat karena pelaksanaan CSR dalam bidang lingkungan.

\section{Pengaruh CSR bidang Sosial terhadap Kinerja Perusahaan yang diukur menggunakan ROE}

Variabel CSR bidang sosial berpengaruh signifikan terhadap Kinerja Perusahaan yang diukur dengan ROE pada perusahaan manufaktur yang terdaftar di ISSI tahun 2017. Hal ini ditunjukan oleh nilai $p$-valuenya sebesar $<0,01$ yang memenuhi kriteria signifikansi yaitu sebesar $<0.05$. Variabel CSR bidang Sosial juga memiliki pengaruh positif terhadap variabel Kinerja Perusahaan yang dapat diamati melalui nilai path coeffisien yang bernilai positif senilai 0,24.

Dimensi sosial merupakan bidang CSR yang paling berhubungan dengan masyarakat seperti halnya dimensi lingkungan. Karena kepercayaan masyarakat merupakan faktor penting dalam citra peruahaan yang akan terbentuk. Masyarakat memiliki pengaruh pada keberadaan serta eksistensi perusahaan. Sehingga aspek sosial memiliki pengaruh pada citra perusahaan. Hal ini menunjukan bahwa dukungan aktif yang diberikan oleh perusahaan dalam kegiatan sosial memberikan pengaruh positif pada masyarakat lingkungan sekitar perusahaan, oleh karena itu masyarakat memiliki opini positif pada citra perusahaan.

\section{KESIMPULAN}

Berdasarkan analisis yang dilakukan dalam penelitian ini dapat disimpulkan bahwa: (i) Pengungkapan CSR secara keseluruhan berpengaruh signifikan positif terhadap kinerja perusahaan pada perusahaan manufaktur yang terdaftar dalam ISSI periode tahun 2017; (ii) Pengungkapan CSR bidang Ekonomi secara tersendiri tidak berpengaruh signifikan terhadap kinerja perusahaan; (iii) Pengungkapan CSR bidang Lingkungan secara tersendiri berpengaruh signifikan terhadap kinerja perusahaan; serta (iv) Pengungkapan CSR bidang Sosial secara tersendiri berpengaruh signifikan terhadap kinerja.

Perbedaan laporan pengungkapan kegiatan CSR dari perusahaan-perusahaan manufaktur yang terdaftar dalam ISSI periode tahun 2017 sangat besar. Ada yang telah membuat laporan pengungkapannya dengan baik dan sesuai namun kebanyakan tidak membuat laporan pengungkapannya dengan baik. Sehingga dapat menimbulkan perbedaan hasil antara pelaksanaan kegiatan 
pertanggungjawaban dengan yang diperoleh dari laporan pengungkapannya.

Seringkali kegiatan tanggung jawab sosial masih tidak sesuai dengan proses perencanaan nasional. Perusahaan banyak yang hanya menyalurkan dana CSR-nya berupa dana sumbangan atau bantuan. Seharusnya dana dapat disalurkan dalam bentuk program-program yang dapat memberikan manfaat bagi kelangsungan lingkungan dan masyarakat.

\section{DAFTAR PUSTAKA}

[1] M. Sueb, "Pengaruh Biaya Sosial terhadap Kinerja Sosial, Keuangan Perusahan Terbuka di Indonesia," in Simposium Nasional Akuntansi IV, Bandung, 2001.

[2] D. Zuhroh and I. P. P. H. Sukmawati, "Analisis Pengaruh Luas Pengungkapan Sosial dalam Laporan Tahunan Perusahaan terhadap Reaksi Investor," in Simposium Nasional Akuntansi VI, Surabaya, 2003.

[3] M. Branco and L. Rodrigues, "Corporate Social Responsibility and Resource-Based," Journal of Business Ethics, vol. 69, no. 2, pp. 111-132, 2006.
[4] L. Dahlia and S. Siregar, "Pengaruh Corporate Social Responsibility Terhadap Kinerja Perusahaan. (Studi Empiris Pada Perusahaan Yang Tercatat di Bursa Efek Indonesia pada Tahun 2005 dan 2006)," in Simposium Nasional Akuntansi IX, Pontianak, 2008.

[5] G. Heal, "Corporate Social Responsibility, An Economic and Financial Framework," The Geneva Papers on Risk and Insurance-Issues and Practice, vol. 30, no. 3, pp. 387409, 2005.

[6] H. Chahal and R. Sharma, "Implications of Corporate Social Responsibility on Marketing Performance: A Conceptual Framework," Journal of Services Research, vol. 1, no. 6, pp. 205-216, 2006.

[7] M. Aryawan, I. K. Rahyuda and N. W. Ekawati, "Pengaruh Faktor Corporate Social Responsibility (Aspek Ekonomi dan Lingkungan) Terhadap Citra Perusahaan," E-Jurnal Manajemen Unud, vol. 2, no. 6, pp. 604-633, 2017. 
Nadya R.G, M. Umar Mai, dan Setiawan, Pengaruh Corporate Social Responsibility... 